\section{Evolução dos acidentes de trânsito em um grande centro urbano, 1991-2000}

\author{
Traffic accidents in a metropolitan area in Brazil, \\ 1991-2000
}

\footnotetext{
1 Secretaria da Saúde do Estado da Bahia, Salvador. Brasil.

2 Instituto de Saúde Coletiva, Universidade Federal da Bahia, Salvador, Brasil.

Correspondência Z. C. Oliveira

Secretaria da Saúde do Estado da Bahia. Rua Areial de Baixo 136 apto. 714, Salvador, BA 40060-210, Brasil. calazanssa@yahoo.com.br
}

\begin{abstract}
A time series study described the trend in motor vehicle accidents from 1991 to 2000, using data from the State Transit Department in Salvador, Bahia State, Brazil. Rates were calculated for total motor vehicle accidents, number of casualties, and standardized mortality based on population and number of vehicles, comparing two periods (1991-1994 and 1995-2000), before and after the adoption of safety measures including compulsory seat belt use and the new National Transit Code (NTC). Vehicle accident and casualty rates were high and showed little variation during the study period. The mortality rate decreased from 25.7/100,000 inhabitants in 1995 to 18.1/100,000 in 1998 and remained stable thereafter. The only significant difference $(p<0.001)$ was in the mean motor vehicle accident mortality rate before and after the intervention. The case fatality rate decreased from $10.7 \%$ (1995) to 7\% (2000). Although still representing a major public health problem in this important metropolitan area, the decrease in motor vehicle accident mortality was possibly due to interventions in 1995 and expanded NTC measures in 1998. Greater efforts to change driver and pedestrian behavior could further decrease the high number of accidents and related mortality.
\end{abstract}

Traffic Accidents; Mortality Rate; External Causes
Zenaide Calazans de Oliveira 1

Eduardo Luiz Andrade Mota 2

Maria da Conceição N. Costa 2

\section{Introdução}

O acelerado processo de urbanização, com crescimento populacional expressivo, e o padrão de ocupação desordenado do solo, observado em décadas recentes nos países em desenvolvimento, produziram efeitos negativos sobre a qualidade do ambiente nas grandes cidades e regiões metropolitanas. No movimento de reorganização do espaço urbano, foram projetadas modificações que tiveram o propósito de facilitar o fluxo e a circulação dos veículos, em número crescente, decorrente da marcada industrialização e expansão das atividades comerciais e o conseqüente aumento da frota de veículos que ocorreram nesses países no século XX, especialmente a partir da década de 50. Para isso, adotou-se um modelo de planejamento que privilegiou o automóvel, como ocorreu em alguns países desenvolvidos, a exemplo dos Estados Unidos 1,2,3.

A elevada freqüência e a gravidade dos acidentes de trânsito encontram-se entre os principais efeitos negativos sobre as condições de saúde da população. Estima-se que, a cada ano, entre 20 e 50 milhões de pessoas são feridas e cerca de 1,2 milhão morrem em acidentes de trânsito em todo o mundo, o que torna estes eventos um dos mais importantes problemas de saúde coletiva. Com efeito, as lesões por acidentes de trânsito respondem por 2,1\% do total de óbitos e por $23 \%$ das mortes por causas externas registradas anualmente em todo o mundo ${ }^{3}$, e figuram entre as 
primeiras causas de óbitos entre os jovens do sexo masculino na faixa etária de 15 a 44 anos 4,5.

O Brasil está entre os países que têm registrado as maiores freqüências de indivíduos feridos por acidentes de trânsito, com taxas que em 2002 alcançaram 219,5 vítimas por 100 mil habitantes 3 e de 19,0 mortes por 100 mil habitantes 6 . Ao lado da grande importância social desses agravos, estima-se que o impacto econômico para o país seja de aproximadamente 5,3 bilhões de Reais, o que equivale a $1 \%$ do Produto Interno Bruto (PIB) nacional por ano 7 .

Em Salvador, Bahia, a taxa de acidentes de trânsito com vítimas alcançou 272 por 100 mil habitantes em 20026 e a mortalidade contribuiu com $22,4 \%$ dos óbitos por causas externas, representando a segunda causa mais freqüente deste grupo, que também ocupa a segunda posição entre todos os grupos de causa de óbito neste município ${ }^{8}$.

A magnitude e as conseqüências da ocorrência de acidentes de trânsito tendem a se modificar ao longo do tempo. Por conseguinte, torna-se necessário ter conhecimento acerca da ocorrência dessas modificações, para que estas informações possam subsidiar o planejamento e as ações de prevenção e controle dessas causas externas de morbidade e mortalidade.

Nessa perspectiva, este estudo tem como objetivo descrever a evolução temporal dos acidentes de trânsito ocorridos no Município de Salvador, no período de 1991 a 2000.

\section{Metodologia}

Realizou-se estudo da evolução temporal dos acidentes de trânsito com vítimas, ocorridos em Salvador, no período de 1991 a 2000, tomando-se como unidade de análise o ano calendário. Foram consideradas como vítimas fatais por acidentes de trânsito tanto as mortes ocorridas no local do acidente, bem como aquelas registradas até trinta dias após a ocorrência do evento, conforme critério adotado pela Associação Brasileira de Normas Técnicas (NBR-10697). A opção por incluir apenas os acidentes de trânsito com vítimas deveu-se à possibilidade dos mesmos apresentarem menor sub-registro em função de envolverem medidas legais e assistência médica.

Salvador, sede da capital do Estado da Bahia, situa-se na Região Nordeste do Brasil. Sua população $100 \%$ urbana aumentou de 2,1 para 2,4 milhões de habitantes entre 1991 e 2000, e está distribuída em uma área territorial de $313 \mathrm{~km}^{2}$, resultando na densidade demográfica para o último ano de 7.805,5 habitantes $/ \mathrm{km}^{2}$. A malha viária urbana é de $1.433,8 \mathrm{~km}$ de extensão para uma frota de quase 412.852 veículos cadastrados. A população de referência do estudo foi constituída pelos residentes nesse município, para cada ano da série analisada.

Para o cálculo das taxas referentes aos anos de 1991, 1996 e 2000, utilizou-se como denominador a população proveniente da contagem populacional e do Censo Demográfico do Instituto Brasileiro de Geografia e Estatística (IBGE). Nos anos intercensitários empregou-se estimativas populacionais fornecidas pela Diretoria de Comunicação e Informação em Saúde (DICS), da Secretaria da Saúde do Estado da Bahia (SESAB). O número anual de acidentes de trânsito com vítimas e das vítimas (incluindo óbitos) por estes eventos foi levantado dos Boletins Estatísticos Anuais, para os anos de 1991 a 2000, do Departamento Estadual de Trânsito da Bahia (DETRAN-BA), onde também foram obtidos os dados referentes ao tamanho da frota de veículos cadastrada. Visando a ampliar a cobertura e melhorar a qualidade das notificações referentes à ocorrência desses agravos, semanalmente o DETRAN-BA realiza uma busca ativa nas unidades para urgência/emergência, referência para a grande maioria dessas vítimas. A seleção de variáveis e indicadores investigados foi baseada no conhecimento existente na literatura específica e na disponibilidade dos mesmos. Foram considerados a idade, sexo e tipo de acidente para a caracterização das vítimas; e para os acidentes: a hora, o dia e o mês de ocorrência.

As taxas globais de acidentes de trânsito com vítimas, taxas de vítimas (feridos + mortos ou com algum tipo de lesão) e taxas de mortalidade devidas a esses agravos foram calculadas por 100 mil habitantes e por 10 mil veículos cadastrados. Calculou-se também a taxa de letalidade (óbitos por acidentes de trânsito sobre o total de vítimas de acidentes de trânsito). Para a caracterização das vítimas foram calculadas as taxas por $100 \mathrm{mil}$ habitantes, distribuídas por faixa etária, para o período de 1994 a 2000. Os intervalos de classe, adotados para as faixas etárias, ficaram condicionados à forma de agregação pela qual esses dados foram disponibilizados pelo DETRAN-BA. Com relação a essa variável foram excluídos os anos de 1991 a 1993, devido ao elevado percentual de vítimas com idade ignorada, que alcançou $57 \%$ entre as vítimas fatais. Por essa mesma razão, somente a partir desse período foram padronizadas por idade as taxas de mortalidade por acidentes de trânsito com vítimas. Para tal, utilizou-se o método direto, tomando-se como população-padrão a de Salvador, do ano 2000.

Foram determinadas as taxas de vítimas e óbitos por 100 mil habitantes: por sexo, a razão de sexo para estas taxas e por tipo de acidente 
(atropelo, colisão, choque, queda, capotamento e outros), para o período de 1998 a 2000. Calculouse ainda as proporções dos acidentes de trânsito (acidente do qual resultou pelo menos um indivíduo ferido) e de acidentes fatais (acidente do qual resultou pelo menos uma morte) por hora, dia da semana e mês de ocorrência para o referido período.

Para os acidentes de trânsito com vítimas e a mortalidade por acidentes de trânsito, avaliou-se a significância estatística da diferença entre valores das médias destes indicadores, calculadas para o período anterior (1991-1995) e posterior (1996-2000) à implementação de um conjunto de medidas dirigidas à redução desses eventos, aqui consideradas como "intervenção", que incluíram o uso obrigatório do cinto de segurança como medida da administração municipal e, posteriormente a implantação do novo Código Nacional de Trânsito, mediante a aplicação de teste $\mathrm{t}$ de Student, aceitando-se nível de significância de 0,05 .

Para o processamento dos dados e elaboração dos gráficos foi utilizado o programa Excel 1997 (Microsoft Corp., Estados Unidos). As análises estatísticas foram realizadas com o emprego do Stata 7.0 (Stata Corp., College Station, Estados Unidos).

\section{Resultados}

Entre 1991 e 2000, foram registrados em Salvador 43.520 acidentes de trânsito com vítimas, o que corresponde a uma média de 11,9 acidentes de trânsito por dia. Esses acidentes produziram 53.858 vítimas, das quais 4.889 (9,1\%) foram fatais, o que equivale a aproximadamente 14,8 vítimas e 1,3 morte por dia, respectivamente. Verificaram-se taxas médias anuais de 195,2 acidentes de trânsito, 241,1 vítimas e 21,9 mortes por 100 mil habitantes. Mais de $70 \%$ do total de vítimas foram do sexo masculino, sendo superior a $80 \%$ entre as vítimas fatais. A razão de sexo para a taxa de mortalidade por acidentes de trânsito foi em média de 4,6, variando de 4,4 a 4,9.

Somente para mortalidade por esse tipo de acidente observou-se uma diminuição de suas taxas (redução de 20,7\%). As colisões ocuparam a segunda posição, representando $27,2 \%$ dos acidentes de trânsito, vindo a seguir as quedas com $7,1 \%$. Os acidentes de trânsito ocorreram com maior freqüência entre às 16 e 19 horas do dia. Mais de 35\% das ocorrências foram registradas entre o sábado e domingo, sendo superior a $40 \%$ para os acidentes fatais. Na distribuição mensal não houve um padrão definido dessas ocorrências.
O atropelo foi o tipo de acidente de trânsito que mais atingiu as vítimas de ambos os sexos, com proporções que variaram de $42,4 \%$ a $46,4 \%$. Desagregando esses acidentes por idade, observou-se que $26 \%$ deles atingiram os indivíduos na faixa etária entre os 18 e 29 anos, e 66,5\% das vítimas foram do sexo masculino. Quando os atropelos são excluídos do total de acidentes de trânsito, observa-se um crescimento de cerca de $43 \%$ nas taxas destes últimos, cuja maior contribuição foi decorrente das colisões, com uma taxa média de $35,3 \%$ e apresentando um aumento de $78 \%$ entre 1991 e 2000 . Também o atropelo foi o tipo de acidente que proporcionou a maior letalidade por acidentes de trânsito, com cerca de $5,2 \%$ da mesma, enquanto a colisão teve uma letalidade de $0,9 \%$.

No período analisado, observou-se que as taxas globais dos acidentes de trânsito e das vítimas destes agravos apresentaram poucas variações (Figura 1). As taxas populacionais de mortalidade tiveram um decréscimo de $21,7 \%$, porém, de fato, esta redução se deu especialmente a partir de 1995 até 1998, quando passou de 25,7 óbitos por 100 mil habitantes, para 18,1 por $100 \mathrm{mil}$, representando uma queda de $29,5 \%$, mantendo-se estável até 2000. A taxa de mortalidade padronizada por idade apresentou evolução semelhante à das taxas brutas para o período. O declínio da letalidade foi de $34,6 \%$, passando de 10,7 óbitos por 100 vitimas em 1995 para 7\% em 2000. No que se refere às taxas dos acidentes de trânsito e de vítimas calculadas em relação ao número de veículos a motor, observa-se decréscimo em quase todo o período (Tabela 1). Entre as vítimas de acidentes de veículos a motor, os acidentes com indivíduos na faixa etária dos 18 aos 33 anos de idade corresponderam a mais de $40 \%$ destes agravos, apresentando também as taxas mais altas e com elevação de sua freqüência no período (Tabela 2). Com referência à mortalidade houve decréscimo em todas as faixas etárias, a exceção do grupo de 18 a 25 anos de idade, no qual se observou um incremento de 19,7\%, entre 1998 e 2000 , passando de 15,5 para 18,5 por $100 \mathrm{mil}$ habitantes. O grupo etário com as taxas de mortalidade mais elevadas foi o de mais de 65 anos de idade (Tabela 3), atingidos com maior freqüência pelos atropelos, com 57,6\% dos acidentes de trânsito.

Foi estatisticamente significante $(\mathrm{p}<0,001)$ a diferença observada entre as médias das taxas de mortalidade por acidentes de trânsito antes do período 1991-1995 (média = 2,1) e do período 1996-2000 (média = 1,8). Para as taxas de acidentes de trânsito com vítimas não se observou qualquer diferença para os dois períodos avaliados (médias $=16,7 ; \mathrm{p}=0,532$ ). 
Evolução das taxas de acidentes de trânsito com vítimas, taxas de vítimas e de mortalidade por estes eventos. Salvador, Bahia, Brasil, 1991-2000.

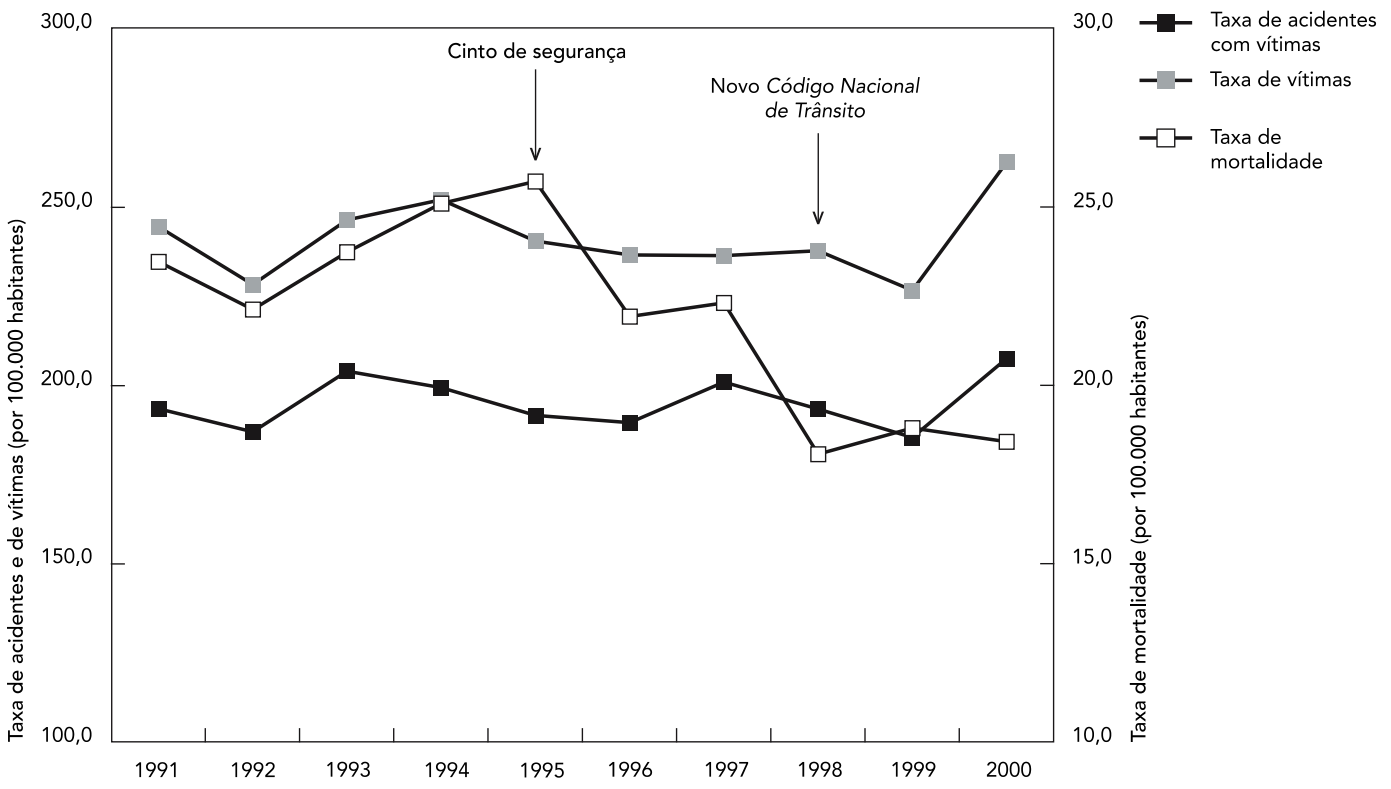

Tabela 1

Evolução das taxas anuais de acidentes de trânsito com vítimas, taxas de vítimas e de mortalidade (por veículos e por habitantes) e taxas de letalidade por estes agravos. Salvador, Bahia, Brasil, 1991-2000.

\begin{tabular}{|c|c|c|c|c|c|c|}
\hline Ano & $\begin{array}{l}\text { Acidentes * com vítimas } \\
\text { (por } 10 \text { mil veículos) }\end{array}$ & $\begin{array}{c}\text { Vítimas ** } \\
\text { (por } 10 \text { mil veículos) }\end{array}$ & $\begin{array}{l}\text { Por } 10 \text { mil } \\
\text { veículos }\end{array}$ & $\begin{array}{c}\text { Mortalidade } \\
\text { Por } 100 \text { mil } \\
\text { habitantes }\end{array}$ & $\begin{array}{c}\text { Por } 100 \text { mil habitantes } \\
\text { (padronização) *** }\end{array}$ & $\begin{array}{c}\text { Letalidade } \\
\text { (óbitos/100 vítimas) }\end{array}$ \\
\hline 1991 & 163,7 & 206,9 & 19,9 & 23,5 & - & 9,6 \\
\hline 1992 & 151,2 & 184,5 & 17,9 & 22,1 & - & 9,7 \\
\hline 1993 & 155,3 & 187,6 & 18,1 & 23,7 & - & 9,6 \\
\hline 1994 & 149,1 & 188,5 & 18,8 & 25,1 & 22,9 & 10,0 \\
\hline 1995 & 142,2 & 178,5 & 19,1 & 25,7 & 24,8 & 10,7 \\
\hline 1996 & 129,2 & 161,3 & 15,0 & 21,9 & 19,9 & 9,3 \\
\hline 1997 & 126,1 & 149,0 & 14,1 & 22,3 & 21,5 & 9,4 \\
\hline 1998 & 114,5 & 142,4 & 10,8 & 18,1 & 16,8 & 7,6 \\
\hline 1999 & 108,6 & 132,8 & 11,0 & 18,8 & 18,5 & 8,3 \\
\hline 2000 & 122,8 & 155,3 & 10,9 & 18,4 & 16,5 & 7,0 \\
\hline
\end{tabular}

Fonte: Departamento Estadual de Trânsito da Bahia/Secretaria da Saúde do Estado da Bahia.

* Acidentes de trânsito dos quais resultou pelo menos um indivíduo ferido, morto ou com lesão;

** Total de vítimas de acidentes de trânsito (mortos + feridos ou com lesão);

*** Padronização pelo método direto, utilizando-se como população padrão a de Salvador, obtida do Censo Demográfico 2000 (Instituto Brasileiro de Geografia e Estatística). 
Tabela 2

Taxas de vítimas * de acidentes de trânsito e variação percentual segundo faixa etária ** e ano de ocorrência. Salvador, Bahia, Brasil, $1994-2000$.

\begin{tabular}{|c|c|c|c|c|c|c|c|c|c|}
\hline Faixa etária (anos) & 1994 & 1995 & 1996 & 1997 & 1998 & $\begin{array}{c}\text { Variação percentual } \\
\qquad(1994-1998)\end{array}$ & 1999 & 2000 & $\begin{array}{c}\text { Variação percentual } \\
(1998-2000)\end{array}$ \\
\hline $0-9$ & 104,3 & 89,6 & 100,8 & 92,4 & 75,1 & $-28,0$ & 85,9 & 100,3 & 33,6 \\
\hline $10-17$ & 199,3 & 190,5 & 180,1 & 157,9 & 153,3 & $-23,1$ & 139,6 & 162,9 & 6,2 \\
\hline $18-25$ & 288,0 & 299,4 & 280,4 & 286,3 & 314,7 & 9,3 & 291,4 & 318,9 & 1,3 \\
\hline $26-33$ & 268,6 & 261,9 & 273,8 & 270,8 & 254,7 & $-5,2$ & 257,2 & 325,9 & 28,0 \\
\hline $34-49$ & 252,9 & 236,0 & 214,4 & 200,9 & 217,5 & $-14,0$ & 215,4 & 227,4 & 4,6 \\
\hline $50-65$ & 229,8 & 221,3 & 184,7 & 178,7 & 188,6 & $-17,9$ & 187,8 & 202,6 & 7,4 \\
\hline$>65$ & 223,5 & 231,5 & 208,1 & 178,6 & 192,9 & $-13,7$ & 177,7 & 168,4 & $-12,7$ \\
\hline Taxa global & 216,4 & 209,2 & 204,7 & 195,4 & 198,7 & $-8,2$ & 193,4 & 221,5 & $-12,7$ \\
\hline
\end{tabular}

Fonte: Departamento Estadual de Trânsito da Bahia.

* Vítimas de acidentes de trânsito (mortos + feridos ou com lesão); taxas por 100 mil habitantes;

** Exclui vítimas com idade ignorada.

Tabela 3

Taxas de mortalidade * por acidentes de trânsito e variação percentual segundo faixa etária e ano de ocorrência. Salvador, Bahia, Brasil, $1994-2000$.

\begin{tabular}{|c|c|c|c|c|c|c|c|c|c|}
\hline Faixa etária (anos) & 1994 & 1995 & 1996 & 1997 & 1998 & $\begin{array}{c}\text { Variação percentual } \\
\qquad(1994-1998)\end{array}$ & 1999 & 2000 & $\begin{array}{c}\text { Variação percentual } \\
(1998-2000)\end{array}$ \\
\hline $0-9$ & 7,3 & 8,2 & 6,2 & 5,1 & 3,0 & $-58,7$ & 3,7 & 5,8 & 91,4 \\
\hline $10-17$ & 14,8 & 11,4 & 8,7 & 11,2 & 9,6 & $-34,9$ & 10,7 & 7,8 & $-19,3$ \\
\hline $18-25$ & 18,9 & 21,7 & 19,1 & 20,9 & 15,5 & $-18,2$ & 17,8 & 18,5 & 19,7 \\
\hline $26-33$ & 22,8 & 27,8 & 24,1 & 25,9 & 19,2 & $-16,0$ & 20,4 & 16,7 & $-12,9$ \\
\hline $34-49$ & 31,6 & 33,5 & 26,9 & 29,4 & 22,9 & $-27,6$ & 26,1 & 21,0 & $-8,2$ \\
\hline $50-65$ & 36,8 & 40,1 & 28,6 & 33,0 & 29,9 & $-18,7$ & 29,6 & 30,0 & 0,3 \\
\hline$>65$ & 58,7 & 67,1 & 52,3 & 48,0 & 37,9 & $-35,4$ & 42,1 & 28,6 & $-24,6$ \\
\hline Taxa global & 21,1 & 22,7 & 21,9 & 20,7 & 16,2 & $-23,1$ & 17,9 & 16,4 & 1,2 \\
\hline
\end{tabular}

Fonte: Departamento Estadual de Trânsito da Bahia.

*Vítimas de acidentes de trânsito (mortos + feridos ou com lesão); taxas por 100 mil habitantes.

\section{Discussão}

Os resultados deste estudo evidenciaram a elevada freqüência com que ocorrem os acidentes de trânsito com vítimas em uma grande área urbana. Os valores das taxas desses acidentes em Salvador superaram as de algumas capitais da Região Nordeste do Brasil 9, representando assim um grave problema de saúde coletiva para a população deste município.

Não obstante as medidas de prevenção adotadas, a evolução dos acidentes de trânsito foi em geral de relativa estabilidade, com algumas flutuações no período. Entre as variações apresentadas, destaca-se a redução dos acidentes e vítimas a partir de 1994, ao tempo em que as mortes decorrentes destes eventos experimentavam ascensão desde 1992 até 1995, sugerindo a ocorrência de maior gravidade dos acidentes em anos recentes, ainda que não se possa descartar uma provável redução do sub-registro dos óbitos por esta causa.

Por outro lado, o acentuado descenso da mortalidade e da letalidade registrado a partir de 1995, ao se desagregar as vítimas de acidentes de trânsito por tipo, aponta para a possibilidade de maior efetividade das medidas de intervenção no que se refere à ocorrência de acidentes fatais, embora deva-se considerar também a hipótese de melhorias no acesso e na qualidade da assistência aos feridos. Em que pese as variações anuais observadas após 1995, foi ex- 
pressiva a redução registrada na mortalidade, e este decréscimo manteve-se, mesmo quando as taxas foram padronizadas por idade, indicando que o mesmo não decorreu de qualquer alteração da estrutura etária da população. Salientase que a referida evolução coincide, no tempo, com o período de intensificação das medidas de prevenção e controle dos acidentes de trânsito que incluíram o uso obrigatório do cinto de segurança, instituído em 199510 e também com a implantação do novo Código Nacional de Trânsito no país, em 1998 11. A partir dessa legislação, diversas medidas de intervenção voltadas para a redução dos acidentes de trânsito foram efetivadas com rigorosa fiscalização e com punições mais severas para os infratores. No entanto, os dados observados para o ano 2000 mostram que as taxas de acidentes e vítimas se apresentaram no mesmo patamar dos anos iniciais da série estudada, o que pode indicar certa insuficiência ou afrouxamento na aplicação dessas medidas.

As medidas implementadas pela legislação do trânsito, de caráter coletivo, parecem ter sido mais eficazes na redução da gravidade desses acidentes, considerando-se que, desde o primeiro ano de sua implementação, acentuou-se a redução que já vinha sendo observada desde 1995 na taxa de mortalidade dos acidentes de trânsito, fenômeno também destacado em outras localidades por alguns autores 12. Como a maior proporção das vítimas fatais de acidentes de trânsito em Salvador é representada por pedestres, é provável que um conjunto de intervenções, tais como: construção de passarelas em pontos estratégicos da cidade; escalonamento do limite de velocidade de acordo com as diferentes vias do sistema viário; redutores de velocidade; disseminação de semáforos; fiscalização eletrônica de velocidade; definição, verificação e controle dos limites mínimos de alcoolemia para os condutores, aliadas ao uso do cinto segurança com maior regularidade por parte dos condutores, tenham contribuído para a queda da mortalidade por acidentes de trânsito. As mortes entre condutores e passageiros contribuíram com elevada proporção desses eventos e apresentaram valores crescentes entre 1991 e 2000. Esses achados apontam para a importância de investimentos em medidas de prevenção dos acidentes de trânsito graves e das lesões fatais. Deve-se, portanto, intensificar a fiscalização e a cobrança do uso obrigatório do cinto de segurança, medida que tem se mostrado eficaz na prevenção das mortes e de ferimentos graves entre os usuários de automóveis, conforme demonstrado por alguns autores 13,14,15.

A diminuição das mortes por atropelo pode ser resultado da redução da exposição dos pe- destres aos acidentes, seja pela maior utilização dos mecanismos de proteção a eles destinados ou pela mudança de sua condição de usuário do espaço viário, passando para a de condutor. Esta hipótese fundamenta-se no fato de que vem ocorrendo um acelerado processo de motorização em Salvador, possivelmente como reflexo indireto da elevação do PIB per capita no período, propiciando maior exposição aos acidentes de trânsito, decorrente do aumento da taxa de motorização e conseqüente aumento do fluxo de veículos, em função da elevação do poder aquisitivo de, pelo menos, parte da população 16,17,18. Também a redução de 16\% do uso de transportes públicos, ocorrida no município entre 1994 e 2000, medida pelo Índice de Passageiro por Quilômetro (IPK) 19, pode ter contribuído para a referida queda. Apesar desse decréscimo, o atropelo continua sendo o tipo mais freqüente de acidente de trânsito, evidenciando a persistência de condições inseguras para a circulação de pedestres.

A estabilidade registrada na curva de mortalidade por acidentes de trânsito nos últimos três anos da série analisada, após um período de franco declínio, pode ser devido a certo afrouxamento na fiscalização das medidas adotadas, bem como do aumento ocorrido, a partir de 1998, do número desses óbitos entre os indivíduos de 18 a 25 anos de idade, visto se tratar de um segmento com peso relativo importante no total das mortes por acidentes de trânsito.

Por sua vez, as flutuações exibidas pelas taxas de vítimas de acidentes de trânsito podem indicar que as intervenções adotadas não foram suficientes para reduzir os acidentes com vítimas, embora tenham produzido efeito positivo no que diz respeito àqueles de maior gravidade, haja vista o decremento observado na mortalidade por estas causas, conforme já referido. Mesmo em países industrializados, onde o declínio da mortalidade por esses acidentes ocorreu desde 1970, ainda são elevadas as taxas de vítimas em alguns deles, onde os investimentos voltados para o ambiente de circulação não têm sido priorizados 20 .

Ainda com relação às vítimas por acidentes de trânsito, destaca-se a participação dos indivíduos entre 18 e 33 anos de idade, que apresentaram taxas crescentes e mais elevadas em todo período do estudo, o que pode ter contribuído para a pequena variação das taxas globais destes eventos. Acredita-se que o padrão apresentado na evolução das taxas nesse grupo populacional pode ser resultado da sua menor aderência às medidas de prevenção adotadas, uma vez que, em geral, os jovens tendem a resistir à mudança, adotando atitudes perigosas na condução de veí- 
culos, como dirigir em alta velocidade, sob efeito de álcool, dentre outras 21,22,23.

Salienta-se que os achados do presente trabalho demandam alguma cautela na sua interpretação. Em primeiro lugar, não se pode ignorar que o reduzido número de anos analisados no estudo pode contribuir para tais resultados, pois, como se sabe, as medidas adotadas para a prevenção da ocorrência dos acidentes de trânsito necessitam de um tempo maior para produzirem os efeitos esperados. Também a utilização de dados secundários pode influenciar esses achados, visto que, para a avaliação dos acidentes de trânsito e agravos deles decorrentes são várias as fontes de informação disponíveis, mas que, entretanto, apresentam limitações. No que diz respeito ao Sistema de Informações sobre Mortalidade (SIM), os dados sobre óbitos devidos a esses agravos apresentam problemas de sub-registro e subnotificação, decorrentes principalmente do não preenchimento da circunstância da causa externa de morte 24,25 .

No Sistema de Informações Hospitalares (SIH), os problemas são da mesma natureza no que se refere aos feridos e mortos por acidentes de trânsito e, mesmo com a obrigatoriedade do registro da circunstância da lesão, a partir do ano de 1998, esta fonte de dados ainda apresenta restrições. Assim, apesar de as informações sobre os acidentes de trânsito e os agravos decorrentes divulgadas pelos Departamentos de Trânsito serem alvo de críticas por parte de alguns autores 26,27, optou-se no presente estudo por utilizar esta fonte de informação em virtude de ser a única que disponibiliza dados sobre acidentes de trânsito, vítimas e óbitos. Além disso, em Salvador essa fonte de dados registrou freqüência de óbitos superior a do SIM e semelhante a do Instituto Médico-Legal Nina Rodrigues (IMLNR), entre 1991 e 2000 .

Outra limitação apresentada por este trabalho, diz respeito aos indicadores de freqüência de acidentes de trânsito, para o qual utilizou-se, no numerador, dados referentes aos acidentes, vítimas e óbitos por local de ocorrência, enquanto no denominador foi considerada a população residente, o que pode resultar em superestimação dos valores. Todavia, há referências de que a maioria dos acidentes de trânsito registrados refere-se à população residente 25,26. Quanto aos indicadores relacionados ao número de veículos e mesmo os populacionais, defrontam-se com as críticas "de conceito". Por exemplo, no caso da frota de veículos cadastrados, além de não circularem na sua totalidade, há a possibilidade de que não se excluam da base de registro aqueles que saíram de circulação; também para os indicadores por habitantes, sabe-se que a população não se encontra permanentemente sob risco. Assim, considera-se que a medida de risco mais próxima da real seria o número de quilômetros rodados por pessoa, e mesmo esta, não estaria considerando os veículos não motorizados, além de apresentarem dificuldades de obtenção dos dados para a sua construção, especialmente, em países em desenvolvimento, onde não são registradas tais informações.

Entende-se, entretanto, que essas limitações não invalidam os resultados encontrados neste trabalho, visto que, por se tratar de um estudo que se refere à evolução no tempo, possivelmente devem expressar uma aproximação da realidade, na medida em que só a partir do último ano da série ocorreram alterações no Sistema de Informações do DETRAN-BA, quando o mesmo foi descentralizado para o município. A aplicação desses dados apresentou um bom potencial para revelar tendências, e sua utilização rotineira certamente contribuirá para a melhoria progressiva da qualidade dos dados registrados, revelando-se as falhas existentes nos sistemas de informações, particularmente no que se refere aos acidentes de trânsito e às vítimas destes agravos.

Conclui-se que, em Salvador, as medidas decorrentes da implementação do novo Código $\mathrm{Na}$ cional de Trânsito devem estar sendo aplicadas de modo insuficiente para obter uma diminuição persistente, em especial na ocorrência dos acidentes de trânsito, possivelmente devido à implantação deficiente do sistema de fiscalização das mesmas. Sugere-se que, ao lado do fortalecimento das intervenções já adotadas, sejam implementadas melhorias no espaço urbano, adequando-o de acordo com o crescimento da frota de veículos ao longo do tempo, e redistribuição mais racional para os diferentes usuários, o que proporcionaria a redução da exposição a esses agravos. 


\section{Resumo}

Este estudo descreve a evolução dos acidentes de trânsito em Salvador, Bahia, Brasil, entre 1991 e 2000, utilizando-se dados do Departamento Estadual de Trânsito do Estado da Bahia. Calculou-se taxas globais dos acidentes de trânsito, vítimas e taxas padronizadas de mortalidade por habitante e por veículos, e comparou-se médias destes indicadores para antes (1991 a 1994) e após (1995 a 2000) a adoção de medidas de intervenção como o uso do cinto de segurança e o Código Nacional de Trânsito. As taxas de acidentes de trânsito e de vítimas apresentaram-se elevadas e estáveis. A mortalidade reduziu entre 1995 e 1998, (25,7/100 mil habitantes e 18,1/100 mil, respectivamente) estabilizando-se posteriormente. A diferença entre médias das taxas de mortalidade foi estatisticamente significante $(p<0,001)$. A letalidade passou de 10,7\% em 1995 para 7\% em 2000. Os acidentes de trânsito representaram importante problema de saúde coletiva na área estudada e a redução da mortalidade sugere impacto positivo das intervenções adotadas, em especial o Código Nacional de Trânsito. A persistência de elevada freqüência de vítimas dos acidentes de trânsito indica a necessidade de intensificar esforços para a mudança de comportamento de motoristas e pedestres.

Acidentes de Trânsito; Coeficiente de Martalidade; Causas Externas

\section{Referências}

1. Vasconcelos EA. Transporte urbano nos países em desenvolvimento: reflexões e propostas. 3a Ed. São Paulo: Editora Annablume; 2000.

2. Rocha FUS. Mobilidade a pé, em Salvador, Bahia [Dissertação de Mestrado]. Salvador: Faculdade de Arquitetura, Universidade Federal da Bahia; 2003.

3. Organización Mundial de la Salud. Informe mundial sobre prevención de los traumatismos causados por el tránsito: resumen. Washington DC: Organización Mundial de la Salud; 2004.

4. Ministério da Saúde. Sistema de Informações sobre Mortalidade. http://www.datasus.gov.br/ tabnet (acessado em 20/Mai/2004).

5. Granados JAT. La reducción del tráfico de automóviles: una política urgente de promoción de la salud. Rev Panam Salud Pública 1998; 3:137-51.

6. Departamento Nacional de Trânsito. Anuário estatístico 2002. http://www.denatran.gov.br/ estatisticas.htm (acessado em 10/Out/2004).

\section{Colaboradores}

Z. C. Oliveira foi responsável pela escolha do tema, desenho do estudo, coleta e análise dos dados, e participou da elaboração da primeira versão do artigo. E. L. A. Mota colaborou para o aperfeiçoamento da metodologia, análise dos dados, revisão da primeira versão do artigo e participou da sua redação final. M. C. N. Costa participou da análise dos dados, revisão da primeira versão do artigo e da sua redação final. Todos os autores contribuíram significantemente para o desenvolvimento deste estudo, inclusive com as sucessivas revisões do texto antes de sua aprovação final.
7. Instituto de Pesquisa Econômica Aplicada/Associação Nacional dos Transportes Públicos. Impactos sociais e econômicos dos acidentes de trânsito nas aglomerações urbanas brasileiras: relatório executivo. Brasília: Instituto de Pesquisa Econômica Aplicada/Associação Nacional dos Transportes Públicos; 2003.

8. Fórum Comunitário de Combate à Violência. O rastro da violência em Salvador - II: mortes de residentes em Salvador, de 1998 a 2001. Relatório de pesquisa. Salvador: Fórum Comunitário de Combate à Violência; 2002.

9. Departamento Nacional de Trânsito. Anuário estatístico 2000. http://www.denatran.gov.br/ estatisticas.htm (acessado em 18/Out/2004). 
10. Prefeitura Municipal de Salvador. Lei no ${ }^{\circ}$ 5012/95, de 25/26 de junho de 1995. Institui o uso obrigatório do cinto de segurança no município de Salvador, Bahia. Diário Oficial do Município de Salvador 1995; 25/26 jun.

11. Departamento Nacional de Trânsito. Código Nacional de Trânsito. http://www.denatran.gov.br/ Legislacao.htm (acessado em 25/Mai/2003).

12. Koushki PA, Bustan MA, Kartam N. Impact of safety belt use on road accident injury and injury type in Kuwait. Accid Anal Prev 2004; 35:237-41.

13. Hijar-Medina MC, Flores-Aldana ME, LópezLópez MV. Cinturón de seguridad y gravidad de lesiones en accidentes de tráfico en carretera. Salud Pública Méx 1996; 38:118-27.

14. Farage L, Colares VS, Cappe Neto M, Moraes MC, Barbosa MC, Branco Jr. JA. As medidas de segurança no trânsito e a mortalidade intra-hospitalar por traumatismo cranioencefálico no Distrito Federal. Rev Assoc Méd Bras 2002; 48:163-6.

15. Bastos YGL, Andrade SM, Cordoni Junior L. Acidentes de trânsito e o novo código de trânsito brasileiro em cidade da Região Sul do Brasil. Inf Epidemiol SUS 1999; 8:37-45.

16. Silva CRL, Kilsztajn S. Acidentes de trânsito, frota de veículos e nível de atividade econômica. Revista de Economia Contemporânea 2003; 7147-59.

17. van Beck EF, Mackenback JP, Looman CWN, Kunst AE. Determinants of traffic accident mortality in the Netherlands: a geographical analysis. Int J Epidemiol 1991; 20:698-706.

18. Söderlund N, Zwi AB. Mortalidad por accidentes de tránsito en países industrializados y en desarrollo. Bol Oficina Sanit Panam 1995; 119:471-81.
19. Secretaria Municipal dos Transportes Urbanos. Anuário de transportes urbanos de Salvador - Ano 14. Salvador: Secretaria Municipal dos Transportes Urbanos; 2002.

20. Regidor ER, Reoyo A, Calle ME, Dominguez V. Fracasso en el control del número de víctimas por accidentes de tráfico en España: a respuesta correcta a la pregunta equivocada. Rev Esp Salud Pública 2000; 76:105-13.

21. Marin L, Queiroz MS. Atualidade dos acidentes de trânsito na era da velocidade: uma visão geral. Cad Saúde Pública 2000; 16:7-21.

22. Marin-León L, Vizzotto MM. Comportamento no trânsito: um estudo epidemiológico com estudantes universitários. Cad Saúde Pública 2003; 19:515-23.

23. Andrade SM, Mello-Jorge MHP. Características das vítimas por acidentes de transportes terrestre em município da Região Sul do Brasil. Rev Saúde Pública 2000; 34:149-56.

24. Mello-Jorge MHP. Mortalidade por causas violentas no município de São Paulo, Brasil. IV - a situação em 1980. Rev Saúde Pública 1982; 16:19-41.

25. Mello-Jorge MHP. Acidentes de transporte terrestre em cidade da Região Sul do Brasil: avaliação da cobertura e qualidade dos dados. Cad Saúde Pública 2001; 17:1449-56.

26. Barros AJD, Amaral RL, Oliveira MSB, Lima SC, Gonçalves EV. Acidentes de trânsito com vítimas: sub-registro, caracterização e letalidade. Cad Saúde Pública 2003; 19:979-86.

27. Kilsztajn S, Silva CRL, Silva DF, Michelin AC, Carvalho AR, Ferraz ILB. Taxa de mortalidade por acidentes de trânsito e frota de veículos. Rev Saúde Pública 2003; 35:262-8.

Recebido em 30/Set/2005

Versão final reapresentada em 28/Jun/2007 Aprovado em 13/Jul/2007 